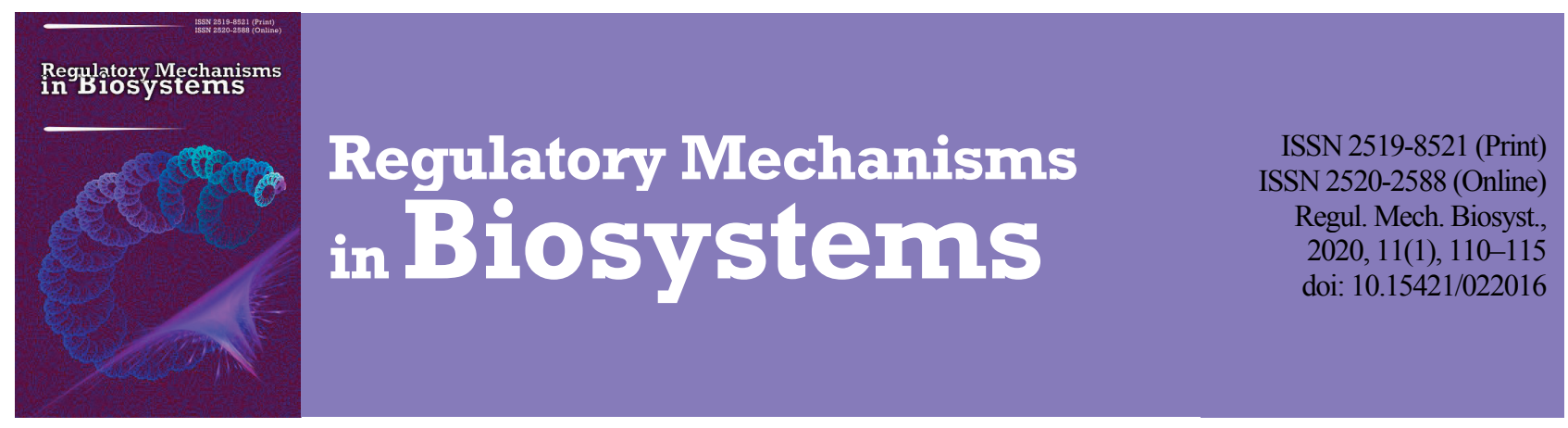

\title{
Event-related potentials during contralateral switching over motor programs in humans
}

\author{
O. V. Korzhyk, O. R. Dmutrotsa, A. I. Poruchynskyi, A. H. Morenko \\ Lesya Ukrainka Eastern European National University, Lutsk, Ukraine
}

Article info

Received 28.12.2019

Received in revised form 22.01.2020

Accepted 24.01.2020

Lesya Ukrainka

Eastern European

National University

Voli 13, Lutsk,

43000, Ukraine.

Tel.: +38-066-826-27-23.

E-mail: Morenko.

Alevtyna@eenu.edu.ua

\begin{abstract}
Korzhyk, O. V., Dmutrotsa, O. R., Poruchynskyi, A. I., \& Morenko, A. H. (2020). Event-related potentials during contralateral switching over motor programs in humans. Regulatory Mechanisms in Biosystems, 11(1), 110-115. doi:10.15421/022016
\end{abstract}

\begin{abstract}
The study of processes related to the motor response suppression and the evaluation of the next, alternative, response after termination of the already observed initial motor response is of significant interest to modern scientists. The objective of our research is to identify the gender-specific features of the amplitude-time characteristics of induced cortical electrical activity in the process of the excitation of the motor programs of manual movement. Healthy and right-handed men and women aged 18-23 participated in the research. The research tasks investigated the time of simple and complex visual-motor responses, amplitude-temporal features of N2 and P3 components of cognitive evoked potentials in the response to launch and contralateral switching (dominant or subdominant arm) of the motor program of finger flexes (pressing the remote control button) in the Stop-Change paradigm. Event-related potentials (ERPs) were analyzed in the frontal, central, and parietal lobes of the cortex. It was established that male participants had lower time indexes of simple and complex visual-motor responses than women. In addition, during the contralateral switching of motor programs of manual movements the smaller latent periods of the ERPs components in the right central and left frontal sections (component N2), in the left hemisphere lobes (component P3) among men were observed. The amplitudes of the N2 and P3 components revealed higher values in male participants at the parietal lobes. Thus, the process of recognizing and differentiating the stimulus among men was faster, with more powerful focus and attention on the operative memory. In the left hemisphere of men and women the smaller latent periods of P3component (in the central lobe) and amplitudes of $\mathrm{N} 2$ and $\mathrm{P} 3$ components were determined compared to the right hemisphere. Thus, the motor programs switching in the paradigm of the experiment occurred with the sequential activation of the left and contralateral right hemispheres.
\end{abstract}

Keywords: manual movements; Stop-Signal task; Stop-Change task.

\section{Introduction}

During social interactions, in the process of learning or teaching, a person constantly controls and designs his or her motor behaviour. Manipulative coordination requires the permanent cancellation and updating of the motor programs and commands. And while the understanding of specific details in terms of these processes in the brain is still limited, the scientific community (Bai et al., 2005; Zimerman \& Hummel, 2010; Krämer et al., 2011) relates MPs to the brain launch and MP stoppage. The so-called Stop-Change paradigm (Logan, 1985; Verbruggen \& Logan, 2008; Rangel-Gomez et al., 2015) is offered for the investigation of the physiological mechanisms of inhibition of one or another process, including the motor response, in the context of a further change to the alternative action. It is worth noting that the amount of research according to the Stop-Change paradigm is very limited.

According to Boecker et al. (2014), the following events (with the occurrence of an alternative problem) can be combined into three groups: the study of cognitive processes (Bai et al., 2005), the study of the full-scale reaction or the flexibility of the reaction (Haalandet al., 2000; Lijffijt et al., 2005; Boecker et al., 2011), and studies that aim to replenish inhibition in its purest form (Stop-Signal Task) and braking, followed by conversion to Stop-Change Task (Band \& van Boxtel, 1999; Boecker et al., 2011; Krämer et al., 2011). In the above-mentioned context, Lijffijt et al. (2005), by studying brain processes among children with attention deficit and hyperactivity disorder, found that the time and effectiveness of inhibitory processes were higher in the task with the emergence of the Stop-Change paradigm, which allowed them to evalu- ate the next, alternative, response after inhibition. Verbruggen \& Logan (2008) raised the question whether inhibition needs a response in the Stop-Change paradigm of the particular Stop-process (with subsequent or parallel execution of an alternative response). In other words, Verbruggen \& Logan (2008) suggested that the initial action may not be suppressed, but may be refracted by the preparation of an alternative response. Camalier et al. (2007), Verbruggen \& Logan (2008) and Boecker et al. (2011) came to the conclusion that experimental results can be further explained by assuming that the Go-response is inhibited by the activation of the Stop-process. However, the alternate Go-response is activated only after the completion of the Stop-process. In this way, all of these processes (Go-Response, Stop-Process, Repeated Go-Response) can be considered independent.

Gender, as a biological characteristic, stimulates different peculiarities of brain processes and, as a consequence, different behaviour of men and women. Some studies revealed a number of sex differences in brain activation (Lissek et at., 2007; Korzhyk et al., 2019). Women in general showed higher cortical activation than men during tapping with either hand, and they exhibited more ipsilateral activation in motortask-relevant regions than men, in particular during finger tapping with the dominant hand (Lissek et al., 2007). Altogether, women showed stronger bilateral cortical activation, whereas men exhibited higher subcortical activation in the basal ganglia. Moreover, in some brain regions, men showed stronger increases of cortical activation than women with increasing task complexity (Lissek et al., 2007). Numerous studies have showed that males are more susceptible to impairment in inhibitory control and increased levels of impulsivity compared with females 
(Gordeev, 2007; Kovalenko, 2009; Mansouri et al., 2009). Schizophrenic patients showed deficits in executive control tests such as stop-signal tasks, and cognitive impairments were much more exaggerated in male patients (Han et al., 2012). In a study by Mansouri et al. (2009) using the stop-signal task, women have shown that they are more capable of resorting to previous influence and practice of using executive control in complex cognitive tasks more than men. Some modifications of neocortical EEG (ERD/ERS) activity were established in the series with cessation of the triggered manual motor program and its subsequent switching over to the alternative movement, compared to those at complete cessation of the movement in men (Korzhyk et al., 2018). The authors revealed comparative decrease in the ERS intensity with respect to the 9, 11, and $16 \mathrm{~Hz}$ oscillations in the fronto-central cortical regions and intensification of ERD at 11 and $16 \mathrm{~Hz}$ in parietal leads; relative intensification of ERS in the left central neocortical zone (11 Hz frequency), that in the right frontal and parietal zones ( $16 \mathrm{~Hz}$ frequency); and ERD for the frequencies of $19-20 \mathrm{~Hz}$ extensively developed in the neocortex (first of all, in the left hemisphere). In contrast to such data, the cortical activity of the female participants in the $\beta 1$-band was lower in ERS EEG $(15-16 \mathrm{~Hz})$ and was marked by the development of ERD EEG (21-22 Hz) than that of men (Korzhyk et al., 2019). The authors noted electrical processes in the cortex in the band of $\beta 2$ activity $(24-26,30-31$ $\mathrm{Hz}$ ) among female participants ERG EEG as opposed to the registered ERD of males. Identified features of brain activity are reflected in the behaviour of men and women. Monsuory et al. (2016) found a significant difference between females and males in benefiting from practice in the stop signal task: the percentage of correct responses in the go trials increased, and the ability to inhibit responses significantly improved, after practice in females.

Despite the significant results of the existing research on the StopChange paradigm, there are some unsolved questions: what mechanisms are involved in the launch situation and the subsequent contralateral switching (dominant / subdominant arm) of the motor programs of the fingers' movements. In addition, the majority of the results do not sufficiently take into account the gender identity of the respondents. For the analysis of the relevant phenomena, it is advisable to use the methodology of registration and assessment of event-related potentials (ERP), which makes it possible to establish successive changes in the amplitude-temporal characteristics of brain activity during stimulus identification, programming and realization of the motor activity (Polish, 2007; Osokina et al., 2016). Their identification and occurrence may open up some perspectives for the qualitative improvement of the early detection of cortical dysfunctions as well as for enriching rehabilitation and management of compulsive behaviour or neuropsychological disorders. The purpose of our study is to find out the features of event-related potentials during contralateral switching (dominant or subdominant arm) of motor programs of manual movements. It is relevant to determine the role of such biological fact as gender identity in the brain processes of the participants in terms of testing. As an extension of this, it can also be suggested that, due to these innate sex differences, optimal rehabilitation treatments could be tailored for females and males.

\section{Materials and methods}

Sixty-five healthy volunteers (32 men and 33 women, 18-23 years old) took part in the tests; the subjects had no psychoneurological disorders and craniocerebral injuries in the anamnesis. All participants demonstrated a right profile of the manual and auditory asymmetry; this was estimated according to the patterns of their responses in the course of questioning and performance of the motor and psychoauditory tests. All tests were carried out in accordance with the fundamental bioethical regulations of the Helsinki Declaration of the World Medical Associations on Ethical Principles of the Performance of Scientific and Medical Examination of Humans (1964-2000), Declaration of Principles of Tolerance (1995), Universal Declaration on Bioethics and Human Rights (1997), Convention of the Council of Europe on Human Rights and Biomedicine (1997), and order No. 66 of the Ministry of Public Health of Ukraine from 13.02.2006. All the tested subjects gave their preliminary written informed consent for their involvement in the tests. All necessary measures were taken to preserve anonymity of the tested subjects. Time (latent periods)of simple sensorimotor responses (SSR) and time of complex sensorimotor responses (CSR) in the choice of one of three objects as signals (triangles, circles, squares)was determined by computer diagnostic complex "Diagnost-1" (Certificate of measuring equipment type № UA-MI/2p-2613-2008 05.08.2008, Ukraine). Visual irritants were used. All participants had to respond to certain stimuli as quickly as possible by pressing and releasing the button panel by the right-hand index finger.

EEG experiment procedure envisioned the use of the Stop-Change task. Beforehand each examinee received an instruction according to which with the appearance of the $1600 \mathrm{~Hz}$ signal, the subject had to rapidly press the right button of the panel with the thumb of the right hand and to release the button. In the case where the stimuli in the pair differed from each other, the triggered motor program (for pressing the left button on the panel by the left-hand thumb) should be inhibited with subsequent switching over to the alternative abovementioned program (Stop-Change) (Fig. 1).

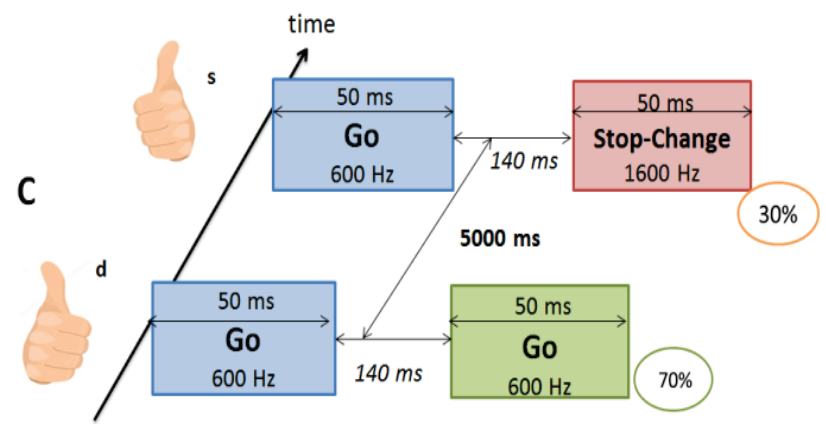

Fig. 1. Scheme of the experiment with the use of the Stop-Change paradigm: Go - the first sound in the stimulus pair; in response to this sound,

the tested subject initiates the movement; Go, or Stop - change are combinations with the second sound in the stimulus pair; $70 \%$ and $30 \%$ are the ratios of the stimulus pairs in the sample; $\mathrm{s}-$ sinister

(left-handed finger), $\mathrm{d}$ - dexter (right-handed finger)

So, under experimental conditions, all stimuli sounds were served in pairs. In some stimuli pairs both sounds were low-pitched, in the others the first sound was of low tone, and the second - high tone. Examinees in each case started moving right-hand thumb at the first sound (Go). The second sound in stimulus pair had confirmation of the value or movement or its switching (Stop-Change). Each acoustic signal lasted $50 \mathrm{~ms}$; the interval between stimulus pairs was $5.0 \mathrm{~s}$ long (Korzhyk et al., 2018, 2019). The ratio of the stimulus pairs with two low-frequency $(600 \mathrm{~Hz})$ tones and pairs with low- and highfrequency (600 and $1600 \mathrm{~Hz}$ ) tones in the test series was $70 / 30 \%$. The delay in presentation of the second sound after the former one in the pair was equal to $140 \mathrm{~ms}$. Therefore, this period corresponded to the sensory (hidden) component of the sensory motor reaction and, partly, to the beginning of the motor component. Consequently, this situation corresponded to the perception of the signal, its analysis, and decision making (decision to perform/ stop/change of the movement) (Sylvester et al., 2003).

During EEG recording, the tested subjects were in a special soundproof and lightproof room, in a semirecumbent position, with their eyes closed. EEG was recorded using standard technical approaches, with a hardware-software complex, Neirokom (NTTs KhAIMedika, Ukraine, certificate of state registration No. 6038/2007 from January 26, 2007). For monopolar EEG recording, active electrodes were positioned according to the international 10/20 system on 19 points of the scalp. Recordings with unpaired indices corresponded to the left hemisphere, and those with paired indices were related to the right hemisphere. Combined contacts on the ear lobules served as a reference electrode. To improve the recording quality, additional reference electrodes between the prefrontal and lateral frontal leads (Ref) and between the right and left anterior frontal leads (N, nazion) were used. Rejection of artifact phenomena from native EEGs was performed using Independent Component Analysis (ICA). 
We analyzed the responses of the subjects to meaningful StopChange stimuli and unmeaningful (Go) stimuli as a differential curve of event-related potentials(ERPs). ERPs were measured as brain responses to a specific cognitive event. The latent period (LP, ms) of the ERPs components (N2, P3), the amplitude (V) of the N2 component (between peaks $\mathrm{P} 2$ and N2) and the P3 component (between peaks N2 and P3) were studied. ERPs were recorded in the frontal (F3, F4), central (C3, C4), and parietal (P3, P4) leads. The choice of such leads is related to the published data (Haaland et al., 2000; Ioffe, 2003; Bai et al., 2005; Korzhyk et al., 2018, 2019) that precisely these cortical areas are most significantly involved in processing of sensorimotor information and motor programming.

The choice of statistical criteria was determined by the patterns of distribution of the obtained numerical data. Testing of the samplings on the normality of their distribution was performed using the ShapiroWilk criterion (W, with $\mathrm{P}>0.05)$. Data for all subjects within the study groups were analyzed by total averaging (grand average). Since the distribution of sensorimotor response time data in the samples was normal, we calculated mean values (x), standard deviations (SD), and error of the mean $( \pm \mathrm{m})$. However, the distribution of ERPs' latent periods and amplitudes data in the samples was different from normal. Therefore, we calculated the median and percentiles (me; 25\%; 75\%) for these samples. Based on such data, intergroup differences were estimated using the ANOVA, the Tukey test (ERPs' latent periods and amplitudes). Significant gender differences (with $\mathrm{P}<0.05$ ) under conditions of tests were estimated. Statistical analysis was performed using Statistica 8.0 (StatSoft Inc.) and Matlab (MathWorks, 2015) software.

\section{Results}

The results of our study revealed a predominance of time of simple (men: $265.7 \pm 15.7 \mathrm{~ms}$, women: $287.9 \pm 16.5 \mathrm{~ms}$ ) and complex (men: $367.3 \pm 17.2 \mathrm{~ms}$, women: $406.0 \pm 19.1 \mathrm{~ms}$ ) sensorimotor response' time in women compared to men ( $\mathrm{P}<0.05$, Fig. 2$)$.

Analysis of the main components of the ERPs during tests allowed us to state that men had shorter latent periods (LPs) of the N2 component in the right central and left frontal leads than those in women.

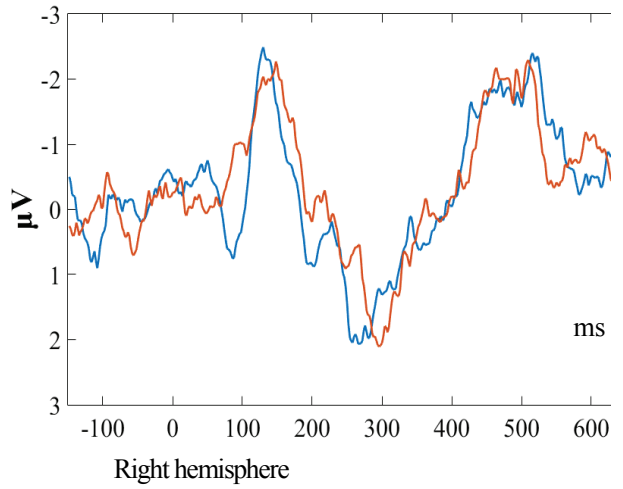

LPs of the P3 component in the male group were shorter in the central and parietal leads of the left hemisphere compared with females ( $\mathrm{P}$ $<0.05$ ). There were shorter LPs of the P3 component in the central lead of the left hemisphere in men and women than those in the right hemisphere $(\mathrm{P}<0.05$, Table 1, 2, Fig. 3-6).
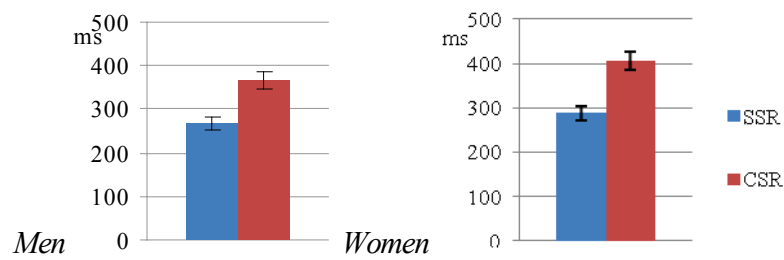

Fig. 2. The latent periods of simple sensomotoric response to visual irritants (SSR) and complex sensomotoric response of one of three stimuli (CSR 1-3) in males and females: * - gender differences, $\mathrm{P}<0.05$

\section{Table 1}

Latent periods of the event-related potentials'components N2 in men and women (median (25\%; $75 \%)$, ms)

\begin{tabular}{rcccc}
\hline Brain & \multicolumn{2}{c}{ Right hemisphere } & \multicolumn{2}{c}{ Left hemisphere } \\
\cline { 2 - 5 } leads & male & female & male & female \\
\hline Frontal & $219(180 ; 246)$ & $222(186 ; 282)$ & $212(178 ; 239)$ & $228^{+}(182 ; 272)$ \\
\hline Central & $202(166 ; 241)$ & $226(174 ; 278)$ & $209(168 ; 242)$ & $216(176 ; 272)$ \\
\hline Parietal & $204(166 ; 232)$ & $212(182 ; 262)$ & $203(181 ; 253)$ & $204(186 ; 268)$ \\
\hline
\end{tabular}

Notes: * - hemispherical differences, $\mathrm{P}<0.05 ;+-$ gender differences, $\mathrm{P}<0.05$.

Table 2

Latent periods of the event-related potentials' components $\mathrm{P} 3$ in men and women (median $(25 \% ; 75 \%), \mathrm{ms})$

\begin{tabular}{ccccc}
\hline \multirow{2}{*}{$\begin{array}{c}\text { Brain } \\
\text { leads }\end{array}$} & \multicolumn{2}{c}{ Right hemisphere } & \multicolumn{2}{c}{ Left hemisphere } \\
\cline { 2 - 5 } male & female & male & female \\
\hline Frontal & $290(246 ; 339)$ & $306(268 ; 358)$ & $286(259 ; 353)$ & $302^{+}(258 ; 348)$ \\
Central & $300 *(253 ; 342)$ & $302^{*}(252 ; 364)$ & $285(246 ; 340)$ & $308^{+}(252 ; 354)$ \\
Parietal & $300(239 ; 356)$ & $292(242 ; 384)$ & $300(257 ; 354)$ & $318^{+}(252 ; 374)$ \\
\hline
\end{tabular}

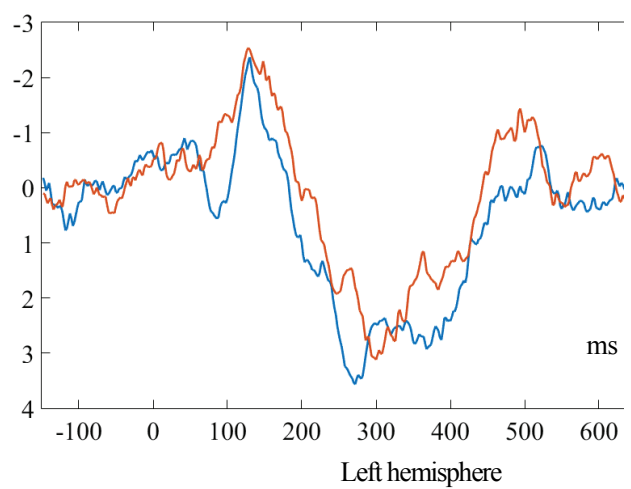

Fig. 3. The event-related potentials in men (blue line) and women (red line) in the frontal leads of the right and left hemispheres during testing: the amplitude and latency data are medians
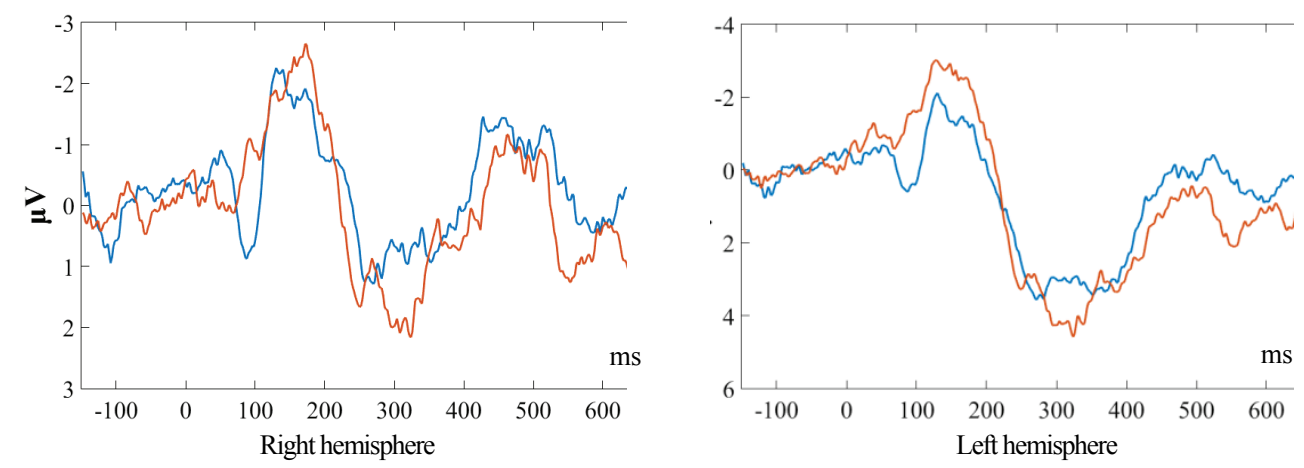

Fig. 4. The event-related potentials in men (blue line) and women (red line) in the central leads of the right and left hemispheres during testing: the amplitude and latency data are medians 
The amplitude of the N2 component of the ERPs estimated between peaks $\mathrm{P} 2$ and $\mathrm{N} 2$ approached a higher value in men in the left parietal lead compared with women $(\mathrm{p}<0.05)$. The amplitude of the ERPs'P3 component was higher in men in the left and right parietal areas than in women

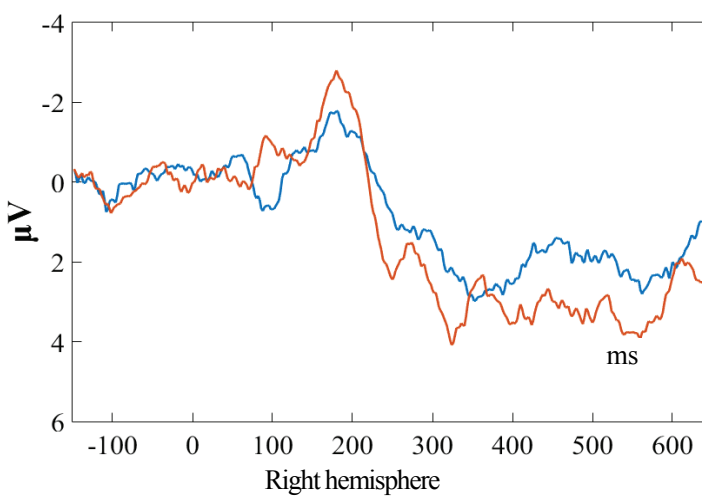

$(\mathrm{P}<0.05)$. In the right hemisphere women had a higher amplitude of the $\mathrm{N} 2$ than in the left one $(\mathrm{P}<0.05)$. A higher amplitude of the $\mathrm{N} 2$ component in the parietal area in the right hemisphere than in the left one was established in men $(\mathrm{P}<0.05$, Table 3, 4, Fig. 3-5, 7).

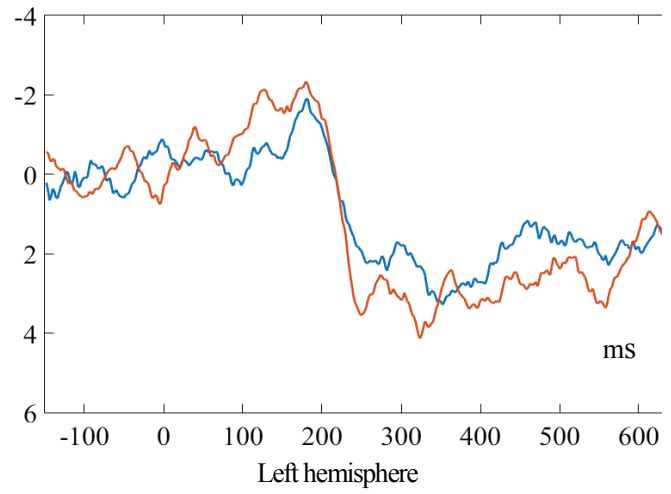

Fig. 5. The event-related potentials in men (blue line) and women (red line) in the parietal leads of the right and left hemispheres during testing: the amplitude and latency data are medians
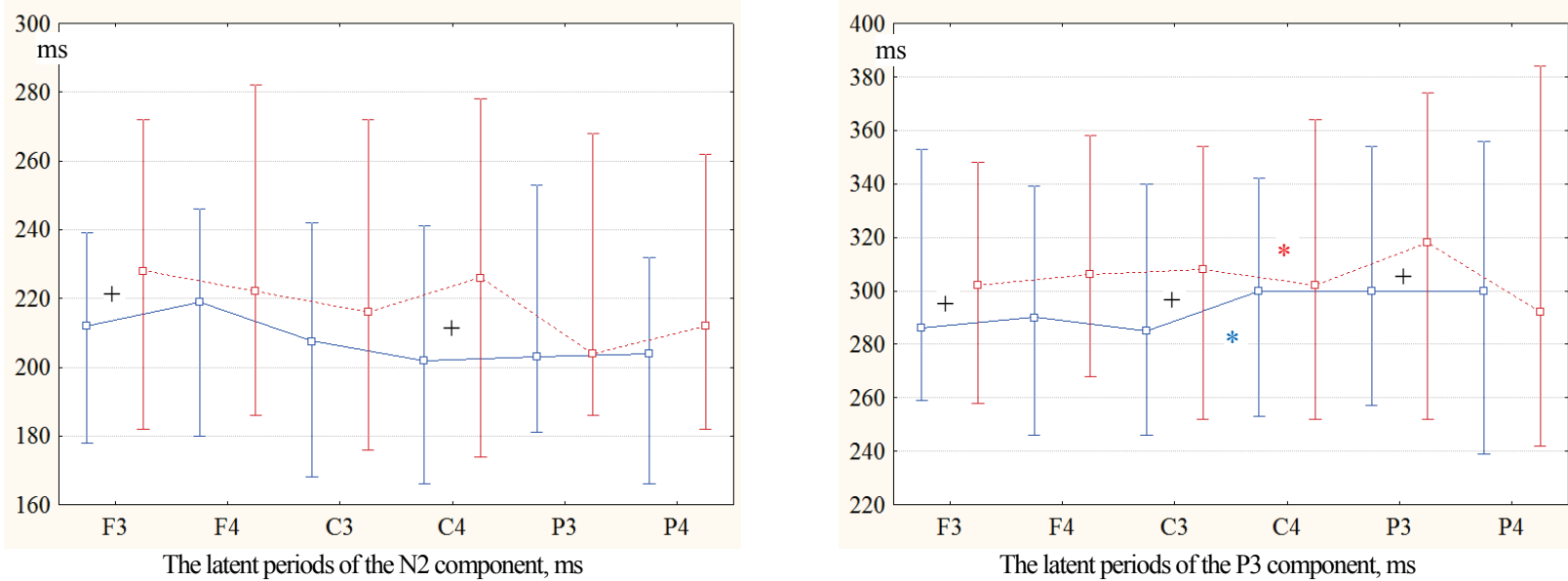

Fig. 6. The latent periods of the event-related potentials' components in men (blue line) and women (red line) in the cortex during testing: the latency data are medians: + gender differences $(\mathrm{P}<0.05)$; hemispherical differences in men $*$ and women $*(\mathrm{P}<0.05)$
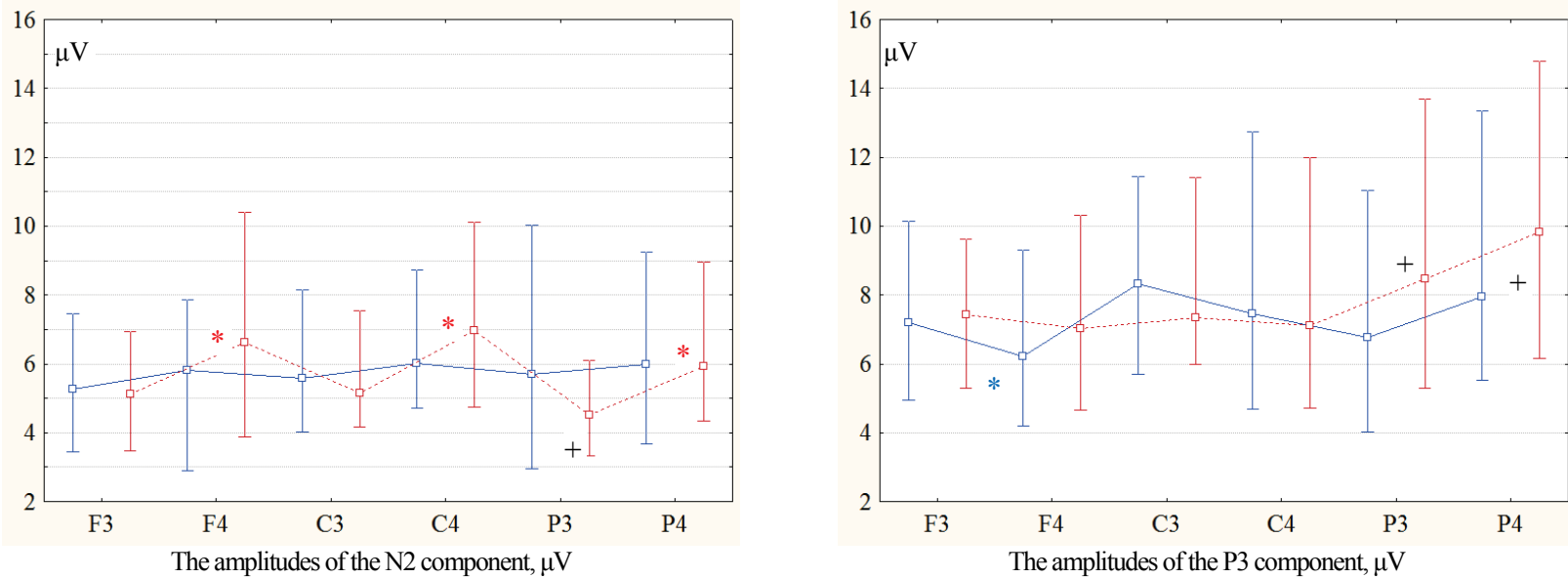

Fig. 7. The amplitudes of the event-related potentials' components in men (blue line) and women (red line) in the cortex during testing: see Fig. 6

Table 3

Peak intervals $\mathrm{P} 2 \mathrm{~N} 2$ of the event-related potentials in men and women (median $(25 \% ; 75 \%), \mu \mathrm{V})$

\begin{tabular}{ccccc}
\hline \multirow{2}{*}{$\begin{array}{c}\text { Brain } \\
\text { leads }\end{array}$} & \multicolumn{2}{c}{ Right hemisphere } & \multicolumn{2}{c}{ Left hemisphere } \\
\cline { 2 - 5 } male & female & male & female \\
\hline Frontal & $5.8(2.8 ; 7.8)$ & $6.6^{*}(3.9 ; 10.4)$ & $5.2(3.4 ; 7.4)$ & $5.1(3.4 ; 6.9)$ \\
Central & $6.0(4.7 ; 8.7)$ & $7.0^{*}(4.7 ; 10.1)$ & $5.6(4.0 ; 8.1)$ & $5.1(4.1 ; 7.5)$ \\
Parietal & $6.0(3.6 ; 9.2)$ & $5.9^{*}(4.3 ; 8.9)$ & $5.7^{+}(3.0 ; 10.0)$ & $4.5(3.3 ; 6.1)$ \\
\hline
\end{tabular}

Table 4

Peak intervals N2P3 of the event-related potentials in men and women (median $(25 \% ; 75 \%), \mu \mathrm{V})$

\begin{tabular}{ccccc}
\hline \multirow{2}{*}{$\begin{array}{c}\text { Brain } \\
\text { leads }\end{array}$} & \multicolumn{2}{c}{ Right hemisphere } & \multicolumn{2}{c}{ Left hemisphere } \\
\cline { 2 - 5 } Frole & female & male & female \\
\hline Frontal & $6.2(4.2 ; 9.3)$ & $7.0(4.6 ; 10.3)$ & $7.2(4.9 ; 10.1)$ & $7.4(5.4 ; 9.6)$ \\
Central & $7.4(4.6 ; 12.7)$ & $7.1(4.7 ; 12.0)$ & $8.3(5.6 ; 11.4)$ & $7.3(6.0 ; 11.4)$ \\
Parietal & $8.0^{*}(5.5 ; 13.3)$ & $9.8^{+}(6.1 ; 14.8)$ & $6.7(4.0 ; 11.0)$ & $8.4^{+}(5.3 ; 13.7)$ \\
\hline
\end{tabular}




\section{Discussion}

Taking into account the available literature, we hypothesised that men and women somewhat differ in features of event-related potentials during contralateral switching (dominant / subdominant arm) of motor programs of manual movements in the go-stop-change paradigm. The statement of such a problem inevitably emphasizes the importance of taking into account the psychophysiological characteristics of the subjects.

We can state that the time of simple and complex visual-motor response was shorter for men than for women, which may indicate the faster processes of central information processing among men. Such behavioural strategies were combined with the characteristic features of brain organization in men and women.

In the context of our study, the latencies and amplitude characteristics of the $\mathrm{N} 2$ and $\mathrm{P} 3$ components of the $\mathrm{P} 300$ wave were analyzed. The positive $\mathrm{P} 300$ wave, occurring between 250 and $450 \mathrm{~ms}$ after stimulation, is one of the important components of evoked potentions (Osokina et al., 2016). Information about it is most closely related to brain cognitive activity, recognition and differentiation of the stimulus, decision making, updating of information in memory (Polich, 2007).The negative component N2 (200-350 ms range) reflects the processes of active selective attention, as well as the process of recognizing the stimulus and comparing it with memory engrams (Osokina et al., 2016), whereas the positive component P3 (300-400 ms range) correlates with attention, control functions, memory.

We have to note that direct comparisons between men and women, conducted in our study revealed a number of sex differences in eventrelated brain activity. During the contralateral switching (right and leftsided) of the motor programs of the manual movements, we found out that the N2 and P3 components of the event-related potentials of men shifted toward smaller values than of women. This pattern reached significance in the right central and left frontal areas (N2 component), in the frontal, central, and parietal leads of the left hemisphere (P3 component). Such a pattern can be explained on the basis of the results (Sulvester et al., 2003; Patel \& Azzam, 2005; Lyzohub et al., 2015), which assume that the process of recognition and differentiation of stimuli of men is faster than of women. In addition, according to Nigg (2000), men were noted for increased attention focusing and involvement of operative memory, compared to women. Previous studies also have shown an increase in the latency of P300 auditory evoked potentials as a result of decreased attention to verbal stimuli, which were repeated (Savostyanov \& Savostyanova, 2003). Furthemore, the brain activation pattern observed was consistent with previous imaging data on finger tapping and sequential finger movements (Ioffe, 2003; Boecker et al., 2011; Krämer et al., 2011; Mansuory et al., 2016).Thus, we assume that the increase of the latency period in the group of women, compared with men, reflects a lower level of their selective attention during performing movements in women. Our assumption correlates well with the findings of the study devoted to examining the role of brain oscillatory systems in the activation and inhibition of motor responses, which showed an increase in the P300 peak latency in ERP per stop signal under the modified paradigm stop signal (Levin et al., 2007). Melynyte et al. (2017) analyzed components of ERP, aimed at assessing the gender impact on the responses in the auditory Go / NoGo experiment. In agreement to our results the authors have shown that females require longer times for monitoring of response conflict (N2s) and outcome inhibition (NoGoP3) than males and more neural resources and longer processing times for motor response execution (Go-P3) (Melynyte et al., 2017). These findings resonate with existing literature data that $\mathrm{NoGo-N} 2$ is related to monitoring of response conflict (Nieuwenhuis et al., 2003; Folstein \& Van Petten, 2008), whereas the NoGo-P3 reflects cancellation of the planned response (Randall \& Smith, 2011). Moreover, some previous studies have shown that women's hormonal background is dependent on Go and No Go responses (Griskova-Bulanova et al., 2016). Here, longer $\mathrm{P} 3$ latencies in females were related to lower progesterone (in the No Go) and higher estradiol levels (in the Go).

The analysis of gender peculiarities of amplitude of the N2 and P3 components showed higher values in men's parietal leads, it could be the criteria of their activation (Harrington et al., 2000; Haaland et al.,
2004; Patel \& Azzam, 2005) in terms of the spacious identification necessity in the process of the activity with the lack of visual control (tests were carried out with closed eyes). At the same time, our results correlate with other studies that have shown that increased cortical activation in a situation of increased attention is most pronounced in the parietal cortex mainly due to an increase in the P3b component (BaranovKrylov et al., 2003). It was also shown earlier that $P 3$ amplitudes positively correlated with the parietal lobe grey matter volumes when response to the rare stimuli was required (Ford et al., 1994). The contralateral switching of motor programs of the manual movements was noted by the shorter LPs of the P3 component in the central lead of the left hemisphere in men and women than in the right hemisphere. Taking into account the above-mentioned data, we can assume that in the process of launching of the motor program of the participants' righthanded movement the left hemisphere was first activated in the central lead, responsible for the memory and launching motor activity (Ioffe, 2003; Mansouri et al., 2016). And the contralateral right hemisphere was more actively involved in the process of motor programs switching with the help of the left hand movement. Our data is consistent with the results obtained during functional magnetic resonance imaging (fMRI) and positron emission tomography (PET) studies (Mansuory et al., 2016). They showed that during simple finger-tapping hemispheric asymmetry is increased, i.e. there is predominantly unilateral activation of the contralateral hemisphere controlling the tapping hand. In addition, this tendency appears to be stronger when tapping with the nondominant hand, thus it is stronger in right-handers with left-handed movements and in left-handers with right-handed movements (Verstynen et al., 2005). However, in contrast to such data, previous studies reported that ipsilateral activation in motor tasks is stronger when the nondominant hand is used (Verstynen et al., 2005). These findings are in line with the notion that the left hemisphere appears to be dominant for fine motor skills performed with either hand (Serrien et al., 2006), particularly in right-handers.

Moreover, in both gender groups, in the leads of the right hemisphere, the higher amplitude of the N2 and P3 components was established. We assume, that it could detect the larger role of the right hemisphere in the process of identification, spacious reflection and motor activity launching. In a number of studies, right-to-left redistribution of the hemispheres' functional activity at different stages of cognitive performance are recorded. Thus, Konstandov assumes that the right hemisphere carries out the initial stage of evaluation of the physical properties of the stimuli, and then the results of this analysis are transferred to the left hemisphere, where semantic analysis and synthesis takes place (Kostandov, 1983) However, according to the theory of hemispheric lateralization, all processes related to mental processing, during the perception of the stimulus and its translation into short-term working memory, content updating and decision-making - mainly occur in the right hemisphere (Bjetsov et al., 2003).

\section{Conclusion}

The results of our research reveal some specific features of cortex electrical activity in men and women during testing. In particular, it was established that male participants had lower time indexes of simple and complex visual-motor responses than women. In addition, during the contralateral switching of motor programs of manual movements the smaller latent periods of the ERPs components in the right central and left frontal areas ( $\mathrm{N} 2$ component), in the left hemisphere leads (P3 component) among men, were observed. The amplitudes of the N2 and P3 components revealed higher values in male participants at the parietal leads. Thus, the process of recognizing and differentiating the stimulus among men was faster, with more powerful focus and attention on the operative memory. In the left hemisphere of men and women the smaller latent periods of the $\mathrm{P} 3$ component (in the central lead) and amplitudes of the $\mathrm{N} 2$ and $\mathrm{P} 3$ components were determined compared to the right hemisphere. Thus, the motor programs switching in the paradigm of the experiment occurred with the sequential activation of the left and contralateral right hemispheres. 


\section{References}

Bai, O., Mari, Z., Vorbach, S., \& Hallet, M. (2005). Asymmetric spatiotemporal patterns of event-related desynchronization preceding voluntary sequential finger movements: A high-resolution EEG study. Clinical Neurophysiology, $116(5), 1213-1221$

Band, G. P., \& van Boxtel, G. J. (1999). Inhibitory motor control in stop paradigms: Review and reinterpretation of neural mechanisms. Acta Psychologica, 101(2-3), 179-211.

Baranov-Kryilov, I. N., Shuvaev, V. T., \& Berlov, D. N. (2003). Dinamika vyizvannyih potentsialov v zavisimosti ot urovnya vnimaniya pri reshenii zritelnoy zadachi [Dynamics of evoked potentials depending on the level of attention when solving a visual problem]. Human Physiology, 29(2), 11-17 (in Russian)

Bjetsov, K. Z., Chermit, K. D., \& Zabolotniy, A. G. (2003). Lateralizatsiya zritelnyih i sluhovyih vyizvannyih potentsialov golovnogo mozga yunoshey [Lateralization of visual and auditory evoked potentials of the brain of young men]. Vestnik Adyigeyskogo Gosudarstvennogo Universiteta, 125, 57-60 (in Russian).

Boecker, M., Drueke, B., Vorhold, V., Knops, A., Philippen, B., \& Gauggel, S. (2011). When response inhibition is followed by response reengagement: An event-related fMRI study. Human Brain Mapping, 32(1), 94-106.

Boecker, M., Gauggel, S., \& Drueke, B. (2014). Stop or stop-change - does it make any difference for the inhibition process? International Journal of Psychophysiology, 87(3), 234-243.

Camalier, C. R., Gotler, A., Murthy, A., Thompson, K. G., Logan, G. D., Palmeri, T. J., \& Schall, J. D. (2007). Dynamics of saccade target selection: Race model analysis of double step and search step saccade production in human and macaque. Vision Research, 47(16), 2187-2211.

Folstein, J. R, \& Van Petten, C. (2008). Inflence of cognitive control and mismatch on the $\mathrm{N}_{2}$ component of the ERP: A review. Psychophysiology, 45(1), $152-170$.

Ford, J. M., Sullivan, E. V., Marsh, L., White, P. M., ab, Lim, K. O., \& Pfefferbaum, A. (1994). The relationship between $P_{300}$ amplitude and regional gray matter volumes depends upon the attentional system engaged. Electroencephalography and Clinical Neurophysiology, 90, 214-228.

Gordeev, S. (2007). Kognitivnyie funktsii i sostoyanie nespetsificheskih sistem mozga pri panicheskih rasstroystvah [Cognitive functions and the state of nonspecific brain systems in case of panic disorders]. Journal of Neurology and Psychiatry Named After S. S. Korsakov, 6, 54-60 (in Russian).

Griskova-Bulanova, I., Griksiene, R., Voicikas, A., \& Ruksenas, O. (2016). Go and NoGo: Modulation of electrophysiological correlates by female sex steroid hormones. Psychopharmacology, 233(13), 2607-2615.

Haaland, K. Y., Elsinger, C. L., Mayer, A. R., Durgerian, S., \& Rao, S. M. (2006) Motor sequence complexity and performing hand produce differential patterns of hemispheric lateralization. Journal of Cognitive Neuroscience, 16(4), $621-636$.

Haaland, K. Y., Harrington, D. L., \& Knight, R. T. (2000). Neural representations of skilled movement. Brain, 123(11), 2306-2313.

Han, M., Huang, X. F., Chen, D., Xiu, M. H., Hui, L., Li, H., Kosten, T. R., \& Zhang, X. Y. (2012). Gender differences in cognitive function of patients with chronic schizophrenia. Progress in Neuro-Psychopharmacology and Biological Psychiatry, 39, 358-363.

Harrington, D. L., Rao, S. M., Haaland, K. Y., Bobholz, J. A., Mayer, A. R., Binderx, J. R., \& Cox, R. W. (2000). Specialized neural systems underlying representation of sequential movements. Journal of Cognitive Neuroscience, 12(1), 56-77.

Ioffe, M. E. (2003). Mozgovyie mehanizmy formirovaniya novyh dvizheniy pri obuchenii: Evoliutsiya klassicheskih predstavleniy [Brain mechanisms for the formation of new movements in training: The evolution of classical representations]. Journal of Higher Nervous Activity Named after I. P. Pavlov, $1,5-21$ (in Russian).

Konstandov, E. A. (1983). Funktsionalnaya asimmetriya mozga i neosoznavaemoe vospriyatie [Functional asymmetry of the brain and unconscious perception]. Nauka, Moscow (in Russian).

Korzhyk, O. V., Morenko, A. G., \& Kotsan, I. Y. (2018). Event-related EEG synchronization/desynchronization under conditions of cessation and switching over of the programs of manual movements in men. Neurophysiology, 50(3), 189-197.

Korzhyk, O., Morenko, O., Morenko, A., \& Kotsan, I. (2019). Gender features of brain processes during inhibition of manual movements' programs. Annals of Neuroscienes, 26(1), 4-9.

Kovalenko, A. (2009). Vliyanie trevozhnosti na vospriyatie emotsional'no znachimyh stimulov u cheloveka [The effect of anxiety on the development of emotionally significant stimuli in humans]. Scientific Notes of the Taurian National University Named After V. I. Vernadskogo, Series "Biology, Chemistry", 22(4), 72 (in Russian)
Krämer, U. M., Knight, R. T., \& Münte, T. F. (2011). Electrophysiological evidence for different inhibitory mechanisms when stopping or changing a planned response. Journal of Cognitive Neuroscienses, 23(9), 2481-2493.

Levin, E. A., Savostyanov, A. N., Lazarenko, D. O., \& Knyazev, G. G. (2007). Rol' ostsilyatornyih sistem golovnogo mozga cheloveka v aktivatsii i tormozhenii dvigatelnyh reaktsiy [The role of the oscillatory systems of the human brain in the activation and inhibition of motor reactions]. Buletin of SO RAMN, 125, 64-72 (in Russian).

Lijffijt, M., Kenemans, J. L., Verbaten, M. N., \& van Engeland, H. (2005). A metaanalytic review of stopping performance in attention-deficithyperactivity disorder: Deficient inhibitory motor control? Journal of Abnormal Psychology, 114(2), 216-222.

Lissek, S., Hausmann, M., Knossalla, F., Peters, S., Nicolas, V., Güntürkün, O., \& Tegenthoff, M. (2007). Sex differences in cortical and subcortical recruitment during simple and complex motor control: An fMRI study. NeuroImage, 37 , 912-926.

Logan, G. D. (1985). On the ability to inhibit simple thoughts and actions: II. Stopsignal studies of repetition priming. Journal of Experimental Psychology. Learning, Memory, and Cognition, 11(4), 675-691.

Lyzohub, V. S., Kozhemiako, T. V., Yukhymenko, L. I., \& Khomenko, S. M. (2015). Elektpofiziolohichni kharakterystyky $\mathrm{P}_{300}$ ta funktsional'na orhanizaciia skladnykh sluhomotornyh reaktsij u pidlitkiv [Electrophysiological characteristics of the $\mathrm{P}_{300}$ and functional organization of complex auditory reactions in adolescents]. Bulletin of the Czech Republic University, Section Biological Sciences, 335(2), 72-78 (in Ukrainian).

Mansouri, F. A., Fehring, D. J., Gaillard, A., Jaberzadeh, S., \& Parkington, H. (2016). Sex dependency of inhibitory control functions. Biology of Sex Differences, 7,11

Melynyte, S., Ruksenas, O., \& Griskova-Bulanova, I. (2017). Sex differences in equiprobable auditory Go/NoGo task: Effects on $\mathrm{N}_{2}$ and $\mathrm{P}_{3}$. Experimental Brain Research, 235, 1565-1574.

Nieuwenhuis, S., Yeung, N., van den Wildenberg, W., \& Ridderinkhof, K. R. (2003). Electrophysiological correlates of anterior cingulate function in a go/no-go task: Effects of response conflct and trial type frequency. Cognitive Affective and Behavioral Neuroscience, 3, 17-26.

Nigg, G. T. (2000). On inhibition/disinhibition in developmental psychopathology: Views from cognitive and personality psychology and a working inhibition taxonomy. Psychological Buleten, 126(2), 220-246.

Osokina, O. I., Ivniev, B. B., \& Putiatin, H. H. (2016). Struktura vyklykanyh potentsialiv golovnogo mozku ta yih osoblyvosti pry deiakyh psyhichnyh rozladakh [Structure of evoked brain potentials and their peculiarities in some psychiatric disorders]. Ukrains'kyi Visnyk Psykhonevrolohii, 24(1), 17-22. (in Ukrainian).

Patel, S. H., \& Azzam, P. N. (2005). Characterization of $\mathrm{N}_{200}$ and $\mathrm{P}_{300}$ : Selected studies of the event related potential. International Journal of Medical Sciences, 2, 147-154.

Polich, J. (2007). Updating $\mathrm{P}_{300}$ : An integrative theory of P3a and P3b. Clinical Neurophysiology, 118, 2128-2148.

Randall, W. M., \& Smith, J. L. (2011). Conflct and inhibition in the cued-Go/NoGo task. Clinical Neurophysiology, 122, 2400-2407.

Rangel-Gomez, M., Knight, R. T., \& Krämer, U. M. (2015). How to stop or change a motor response: Laplacian and independent component analysis approach. International Journal of Psychophysiology, 97(3), 233-244.

Savostyanov, A. N., \& Savostyanova, D. A. (2003). Izmeneniya elektricheskoy aktivnosti mozga vo vremya pryivyikaniya $\mathrm{k}$ verbalnomu stimulu $\mathrm{u}$ ispyituemih s vyisokim i nizkim urovnem lichnostnoy trevojnosti [Changes in the electrical activity of the brain during adaptation to a verbal stimulus in subjects with high and low levels of personal anxiety]. Journal of Higher Nervous Activity Named After I. P. Pavlov, 53(3), 351-360 (in Russian).

Serrien, D. J., Ivry, R. B., \& Swinnen, S. P. (2006). Dynamics of hemispheric specialization and integration in the context of motor control. Nature Reviews Neuroscience, 7, 160-167.

Sylvester, C. Y., Wager, T. D., Lacey, S. C., Hernandez, L., Nichols, T. E., Smith, E. E., \& Jonides, J. (2003). Switching attention and resolving interference: fMRI measures of executive functions. Neuropsychologia, 41(3), 357-370.

Verbruggen, F., \& Logan, G. D. (2008). Response inhibition in the stop-signal paradigm. Trends Cognitive Science, 2(11), 418-424.

Verstynen, T., Diedrichsen, J., Albert, N., Aparicio, P., \& Ivry, R. B. (2005). Ipsilateral motor cortex activity during unimanual hand movements relates to task complexity. Journal of Neurophysiology, 93, 1209-1222.

Zimerman, M., \& Hummel, F. C. (2010). Non-invasive brain stimulation: Enhancing motor and cognitive functions in healthy old subjects. Front Aging Neurosciences, 2, 149 